$\xi=$

\title{
Mineralisation of natural rubber (poly cis 1-4 isoprene) by co-cultured bacterial strains isolated from rubber plantation area
}

\author{
Manasa Muralidharan, Veena Gayathri Krishnaswamy* \\ Department of Biotechnology Stella Maris College, Chennai-87, Tamilnadu, India \\ *Corresponding author E-mail: veenagayathri@yahoo.com
}

\begin{abstract}
Objective: To isolate Natural Rubber degrading Bacterial co-cultures from rubber plantation soil and to characterize and identify the organisms by $16 \mathrm{~s} r$ RNA sequencing.

Methods: Cocultures of the bacteria were isolated from the contaminated site by enrichment culture technique. Plate assay method and liquid assay method by using Mineral Salt Medium was followed for screening of bacteria for its capacity to mineralize Natural rubber. Degradation was confirmed by Spectrophotmetric and Fourier Transform Infra-Red (FTIR) studies.Natural rubber degraded by the cocultures were studied at different concentrations and the physico-chemical analysis were optimized ( $\mathrm{pH}$, temperature, carbon and nitrogen sources)

Results: Isolated organism was identified as Bacillus cohnii and Brevundimonas naejangsanensis. The co-cultures were able to utilize the Natural rubber which was confirmed by Spectrophotometric and FTIR studies. From the current study it was evaluated that Natural rubber was mineralized up to $50 \%$ where optimum concentration was $10 \%$.

Conclusion: From current investigation, it can be concluded that our isolated bacterial cocultures Bacillus cohnii and Brevundimonas naejangsanensis have the capacity to mineralize Natural rubber and hence such isolated cocultures can be used in removal of from waste Natural rubber products in the environment.
\end{abstract}

Keywords: Bacillus cohnii; Brevundimonas naejangsanensis; Natural Rubber; Mineralisation 16s r RNA sequencing.

\section{Introduction}

Rubber products are widely used in our daily life these products are mainly made up of Natural rubber (NR) or cis-1, 4 polyisoprene, Natural rubber (NR) or poly (cis-1,4-isoprene), is by qualitative and quantitative criteria, one of the most important biopolymer. For almost a hundred years, millions of tons of NR Derived products have been produced by humankind. In addition, NR and other polyisoprene are produced by thousands of plant species. (Omo-Ikerodah et al., 2009).

Rubber trees are basically found in tropical and semitropical countries. Indonesia, Malaysia, Sri Lanka, South America and India (especially Kerala, Tamilnadu and Karnataka) have abundant resource of natural rubber. The global rubber consumption is estimated to be 12.5 million metric tons in 2013 of which $65 \%$ were used for tire production and other $35 \%$ is used for the production of other rubber products.

Several environmental problems are caused by the dumping or from the effluents of the rubber industry. Wastewater discharged from latex rubber processing usually contains high level of BOD. Thus causing a great threat to the water bodies, the most common methods to cope with this problem are to burn the tires in cement kilns and power plants or to use them as artificial reefs. However these methods further cause environmental problems. (Fatta et al., 1999). The wastage of valuable fossil fuels and the disposal of solid have become two major problems of rubber industry leading to the environment pollution. Thus various physical, chemical and biological methods have been proposed to solve this problem. But these physical and chemical techniques cause a great threat to environment.

One way of overcoming the environmental problems is provided by microbial transformation of rubber into useful products. There are some specific advantages of biotechnological processes compared to chemical and physical ones. However, there are still some obstacles, most notably the sensitivity of chemicals towards most chemicals, including rubber additives which are used to improve stability and function of tires over a wide temperature range.

First studies on microbial degradation of natural rubber were already done about 100 years ago. However, until now only little is known about the molecular fundamentals and the biochemistry of poly (cis-1, 4-isoprene) degradation. Poly (cis-1,4-isoprene) is the main constituent (> $90 \%$ of dry weight) of natural rubber (NR), a biopolymer synthesized by many plant species and some fungi in varying degrees of quality and quantity (Braaz et al.,2004).

Hence the present study focuses on the mineralization of Natural Rubber by co-cultured bacterial strains isolated from contaminated soil of rubber plantation area. Their growth conditions were optimized for maximum mineralization of Natural Rubber. The mineralization was confirmed by FTIR studies and SEM observations. The co-cultured bacterial strains were biochemically characterized and molecularly identified by $16 \mathrm{~s} r$ RNA sequencing. 


\section{Materials and methods}

\subsection{Sample collection}

The soil sample was collected from rubber plantation area in Wayanad under aseptic conditions in plastic covers. They were collected from the rooting part of the rubber trees. The collected samples were transferred to the laboratory under aseptic conditions.

\subsection{Acclimatization}

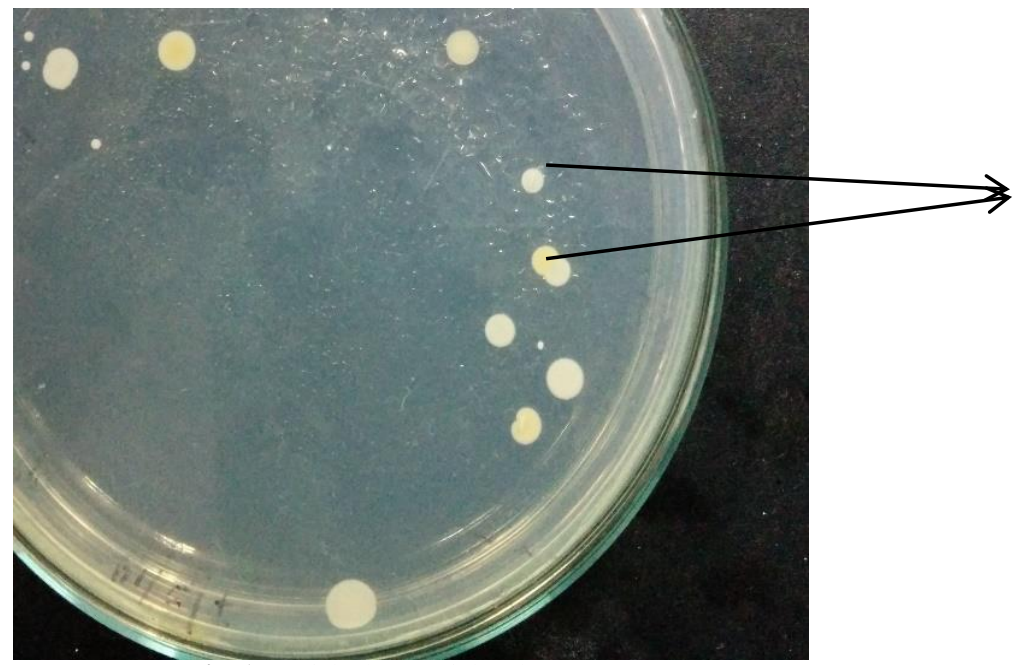

White and Yellow colonies

For acclimatization and enrichment of the strains $150 \mathrm{ml}$ mineral salts medium was prepared in conical flasks having the composition: Di-potassium hydrogen phosphate $\left(\mathrm{K}_{2} \mathrm{HPO}_{4}\right)-1 \mathrm{~g} / \mathrm{L}$, Magnesium sulphate $\left(\mathrm{MgSO}_{4} .7 \mathrm{H}_{2} 0\right)$ - $0.5 \mathrm{~g} / \mathrm{L}$, Potassium nitrate $\left(\mathrm{KNO}_{3}\right)$ $1 \mathrm{~g} / \mathrm{L}$. To the conical flask $2 \mathrm{ml}$ of latex and 5 grams of the collected soil sample was inoculated. Then it was kept for incubation. After the incubation the microbial growth was observed for morphological identification under microscope. A viable growth was observed under microscope. Then further sub culturing was done at 24 hours interval. Figure 1 shows the co-cultures enriched in Mineral Salts Medium.

Fig. 1: Enriched Bacterial Cultures.

\subsection{Determination of the molecular weight of the NR- latex solution}

For the proper evaluation of the average molecular weight of the collected NR-latex solution a capillary Ubbelohde viscometer was used. Then according to the time taken by each of those samples to reach their specific end point in the viscometer, the specific viscosity was calculated for each sample. The formula used for the calculation of the specific viscosity is given by:

Specific viscosity $\eta_{s p}=t_{s}-t_{o} / t_{o}$

Where, $\mathrm{t}_{\mathrm{s}}$ is the time taken by the sample and $\mathrm{t}_{\mathrm{o}} \mathrm{is}$ the time taken by distilled water

\subsection{Calculation of the molecular weight of the natural rubber latex used in the experiment}

The method widely used in the determination of the molecular weight is based upon the determination of the intrinsic viscosity $[\eta]$ of a polymer in the solution through measurements of the solution viscosity. Molecular weight is calculated by the MarkHouwink equation (Fried 2005) given as,

$[\eta]=\mathrm{KM}_{\mathrm{v}}{ }^{\alpha}$

Where, $\mathrm{M}_{\mathrm{V}}$ is the viscosity - average molecular weight. Both $\mathrm{K}$ and $\alpha$ are empirical constants that are specific for a given polymer, solvent and temperature. The molecular weight of the natural rubber latex used was found to be 21379.62 .

\subsection{Isolation of bacterial consortium from enriched mineral salts medium}

Using the culture broth serial dilution and pour plate technique was performed on sterile
Nutrient agar plates for the dilutions- $10^{-8}, 10^{-9}$ and $10^{-10}$. Bacterial strains which were

Morphologically different were identified and pure cultures of these were maintained.

\subsection{Determination of the mineralization rate of the nat- ural rubber latex and growth pattern of the bacterial con- sortium}

The mineralization rate of natural rubber latex in the study was determined by the titrimetric method (Warnekee et al.,2007) and the growth pattern of the organism was observed by checking the growth OD every 24 hrs for 5 days. Evidence for biodegradation of the poly (cis-1, 4-isoprene) and poly (trans-1, 4-isoprene) hydrocarbon chains to $\mathrm{CO}_{2}$ was obtained by the determination of the respiratory $\mathrm{CO}_{2}$ released during the cultivation of the cells in the presence of isoprene as sole carbon source. Determination was carried out in a tightly closed glass bottles by using the property $\mathrm{Ba}(\mathrm{OH})_{2}$ to precipitate $\mathrm{CO}_{2}$ into $\mathrm{BaCO}_{3}$. The mineral salts medium was sterilized and dispensed in bottles. Further latex and cocultured bacterial strains were added in equal concentration was inoculated. This was connected using pipes to another bottle containing $15 \mathrm{ml}$ of $0.2 \mathrm{M}$ Barium hydroxide solution.The experimental set-up for the mineralization study is shown in the Figure 2. Quantitative estimation of $\mathrm{BaCO}_{3}$ was done by titrating it against $1 \mathrm{~N} \mathrm{HCl}$. (Warnekeeet al., 2007).

Mineralization was calculated using the following formula:

Mineralization $\left(\% \mathrm{CO}_{2}\right)=$ required amount of $\mathrm{HCl}(\mathrm{ml}) \times 1 / \mathrm{C}$ content of amount of poly (1, 4- isoprene) applied (mmol) x 2 .

As an indicator, phenolphthalein was added and the end point was determined by alteration of the colour from pink to colourless. 


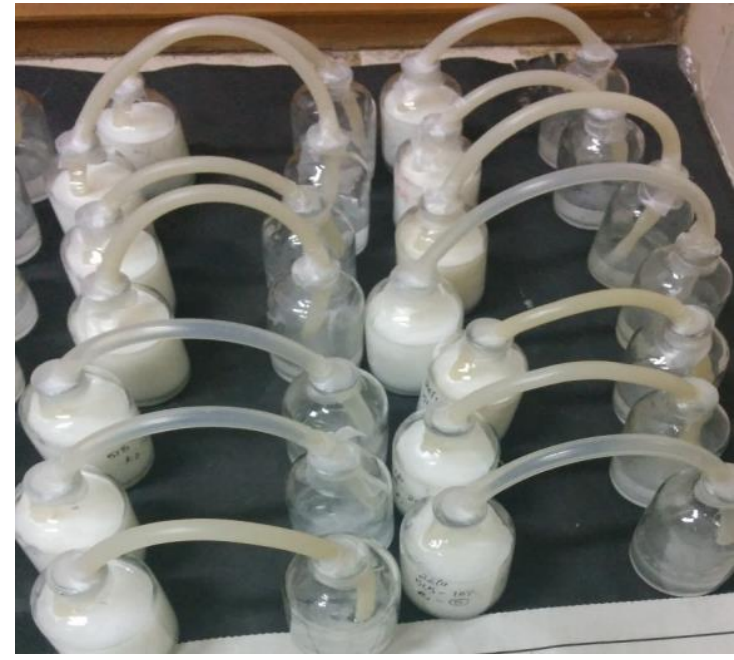

Fig. 2: Experimental set-up for Mineralization of Latex.

\subsection{Mineralization of different concentrations of latex}

To study the mineralization of different concentration of NR latex $(10 \%, 20 \%, 30 \%, 40 \%, \& 50 \%)$ the bacterial co-culture was inoculated in each of these. Then the bottles were connected to the Ba $(\mathrm{OH})_{2}$ using plastic pipes and these were properly sealed. The set up was incubated in room temperature. Mineralization was studied and quantitative estimation of $\mathrm{BaCO}_{3}$ was done by titrating it against $1 \mathrm{~N} \mathrm{HCl}$ (Warnekeeet al., 2007) every 24 hrs for 5 days.

\subsection{Optimization of growth in different $\mathrm{pH}$ and tem- perature}

In the optimum concentration of latex, optimization studies were performed by varying the $\mathrm{pH}$ and temperature. Media was prepared in different $\mathrm{pH}$ ranging from 8 to $10(8,8.5,9,9.5$, and 10$)$ and different temperatures $\left(28^{\circ} \mathrm{c}, 37^{\circ} \mathrm{c}, 45^{\circ} \mathrm{c}\right)$. Mineralization was studied and quantitative estimation of $\mathrm{BaCO}_{3}$ was done by titrating it against $1 \mathrm{~N} \mathrm{HCl}$ (Warnekeeet al., 2007) every 24hrs for 5 days.

\subsection{Optimization studies by varying the carbon and nitrogen sources}

In the optimum concentration of NR and optimum $\mathrm{pH}$ and Temperature, studies were performed by using different carbon and nitrogen sources. $0.1 \%$ of different carbon (sucrose, galactose, xylose, maltose) and nitrogen (peptone, ammonium nitrate, yeast extract, tween) sources were used. Mineralization was studied and quantitative estimation of $\mathrm{BaCO}_{3}$ was done by titrating it against $1 \mathrm{~N} \mathrm{HCl}$ (Warnekeeet al., 2007) every 24hrs for 5 days.

\subsection{To study the products produced by mineralization of (poly-1, 4-cis-isoprene)}

Chemical changes that arose directly on the natural rubber surface as a result of the mineralization were determined using FTIR Spectroscopy. It was performed in Perkin Elmer

Spectrum from IIT Chennai. The samples were studied in a transmittance spectra of IR range 4000 to 400nm (Roy et al., 2005).

\subsection{Biochemical characterization}

The bacterial strain isolated was studied for Morphological and Biochemical characteristics. Initially, Gram staining and motility test were performed after which biochemical characterization was done (with Himedia, India) to identify the phenotypic characters of the Bacterial strains. Catalase, Oxidase, Urease, IMViC and Triple Sugar Iron Agar Tests were performed to determine the Biochemical characteristics of the isolate. After $24 \mathrm{~h}$ incubation at $37^{\circ} \mathrm{C}$, the colour change observed was determined as posi- tive/negative result. Genus level identification of the unknown bacterial strain was accomplished by using Bergey's Manual of Systematic Bacteriology (2005)

\subsection{Molecular characterization of individual isolates}

Chromosomal DNA was isolated from the pure strain by the standard phenol/chloroform extraction method. The 1.2 kilo base partial sequence of the 16S r RNA gene was amplified from the chromosomal DNA using polymerase chain reaction (PCR) with universal Eubacteria-specific primers 16F27 (5'-CCA GAG TTT GAT CMT GGC TCA G-3') and 16R1525XP (5'-TTCTGCAGT CTA GAA GGA GGT GWT CCA GCC-3'). The PCR conditions used were an initial denaturation at $94^{\circ} \mathrm{C}$ for two minutes, followed by 35 cycles of denaturation at $95^{\circ} \mathrm{C}$ for one minute, annealing at $55^{\circ} \mathrm{C}$ for one minute, and extension at $72^{\circ} \mathrm{C}$ for one minute, and a final extension at $72^{\circ} \mathrm{C}$ for 10 minutes and sequenced on an ABI310 automated DNA sequencer using the Big Dye terminator kit (Applied Biosystems 3730 x DNA Analyzer). The amplified 16S r RNA gene PCR products from these isolates were directly sequenced after purification by precipitation with polyethylene glycol and $\mathrm{NaCl}$. The primers used to obtain the complete sequence of $16 \mathrm{~S} \mathrm{r}$ RNA gene of the isolates were the same as for PCR amplification (16F27N and 16R1525XP).

Sequence data analysis was done using ChromasPro and Sequencing Analysis software. Further, phylogenetic tree was constructed using MEGA6. The evolutionary history was inferred using the Neighbour-Joining method.The optimal tree with the sum of branch length $=0.04720271$ is shown. The tree is drawn to scale, with branch lengths (next to the branches) in the same units as those of the evolutionary distances used to infer the phylogenetic tree. The evolutionary distances were computed using the Maximum Composite Likelihood method and are in the units of the number of base substitutions per site. The analysis involved 14 nucleotide sequences. Codon positions included were $1 \mathrm{st}+2 \mathrm{nd}+3 \mathrm{rd}+$ Noncoding. All positions containing gaps and missing data were eliminated. There were a total of 694 positions in the final dataset. Evolutionary analyses were conducted using MEGA6.

\section{Results}

\subsection{Growth pattern and mineralization of natural rub- ber latex by the bacterial consortium}

At the beginning we undertook several unsuccessful attempts to enrich NR-degrading bacteria from various soil samples. We then used contaminated soil samples taken from the neighborhood of NR-producing plants, expecting that in decaying plant material NR-degrading bacteria would naturally be enriched. Figure 3 shows the growth and mineralization of latex by the isolated cocultured bacterial strains. At the end of the experiment it was noted that the co-cultured bacterial strains showed maximum growth on the $3^{\text {rd }}$ Day and mineralization of $\left(3.2 \times 10^{-5}\right)$ on the $4^{\text {th }}$ Day.

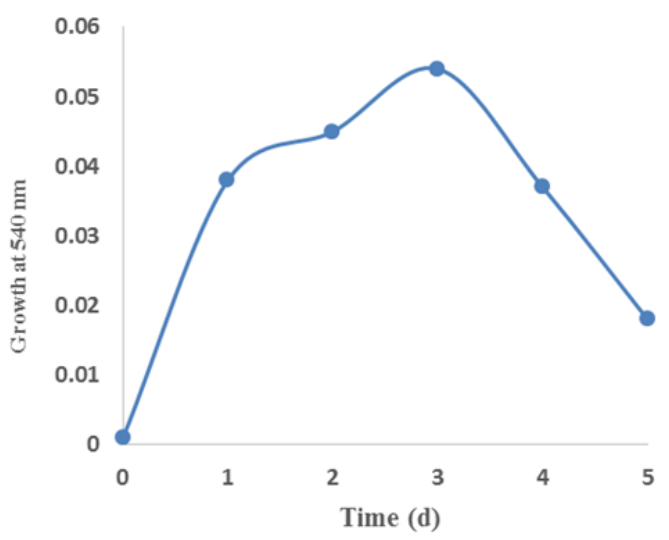




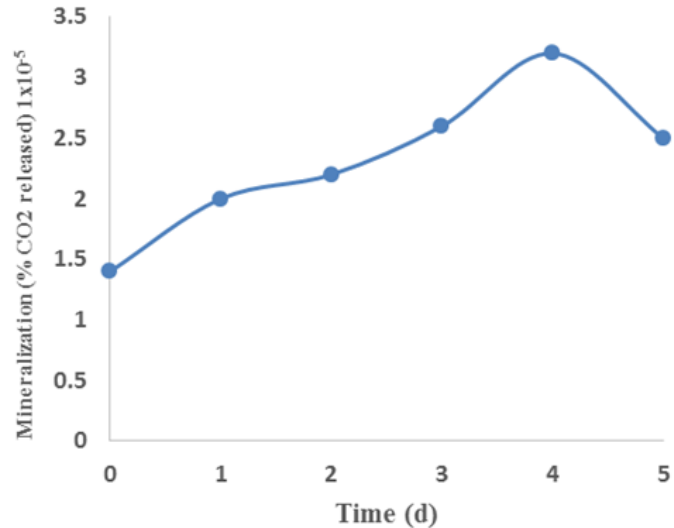

Fig. 3: Growth and Mineralization of Natural Rubber Latex

\subsubsection{Mineralization of different concentrations of natural rubber latex}

To study the mineralization and growth of the co-cultured bacterial strains on different concentration of latex $(10 \%, 20 \%, 30 \%$, $40 \%$ and $50 \%$ ) isolated bacterial strains were cultured in Mineral Salts Medium containing different concentrations of latex. Figure 4 shows the growth and mineralization of different concentration of latex by the co-cultured strains. At the end of the experiment it was noted that the co-cultured bacterial strains showed maximum growth on the $3^{\text {rd }}$ Day and mineralization of $\left(3.6 \times 10^{-5}\right)$ on the $4^{\text {th }}$ Day
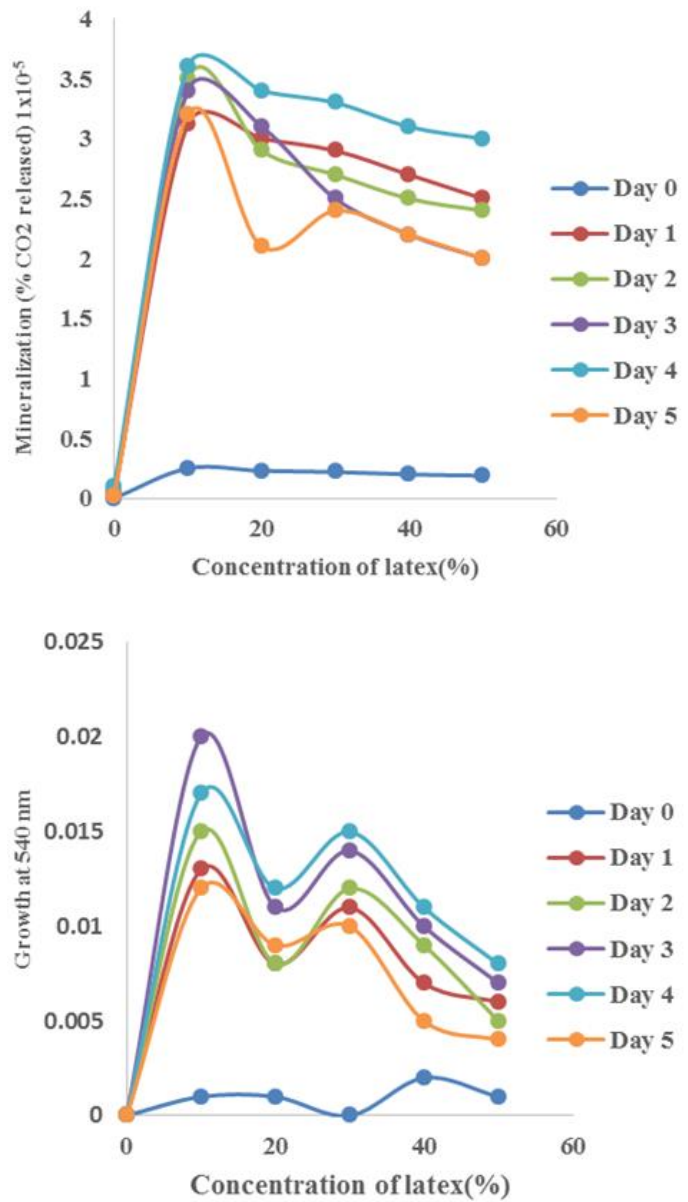

Fig. 4: Growth and Mineralization of Different Concentrations of Natural Rubber Latex.

\subsubsection{Optimization studies by varying the $\mathbf{P H}$}

To study the growth of the co-cultured bacterial strains on different $\mathrm{pH}(8,8.5,9,9.5$ and 10$)$ the isolated co-cultured strains were inoculated in Mineral Salts Medium with optimum concentration of $10 \%$ latex solution and different $\mathrm{pH}$. Figure 5 shows the growth and mineralization in different $\mathrm{pH}$ by the co-cultured bacterial strains. At the end of the experiment it was noted that the cocultured Bacterial strains showed efficient growth and mineralization in the $\mathrm{pH} 9$. Maximum growth on $2^{\text {nd }}$ Day and mineralization of $\left(6.48 \times 10^{-5}\right)$ on the $3^{\text {rd }}$ Day indicated that the co-cultured bacterial strains were efficient in mineralization in alkaline condition.
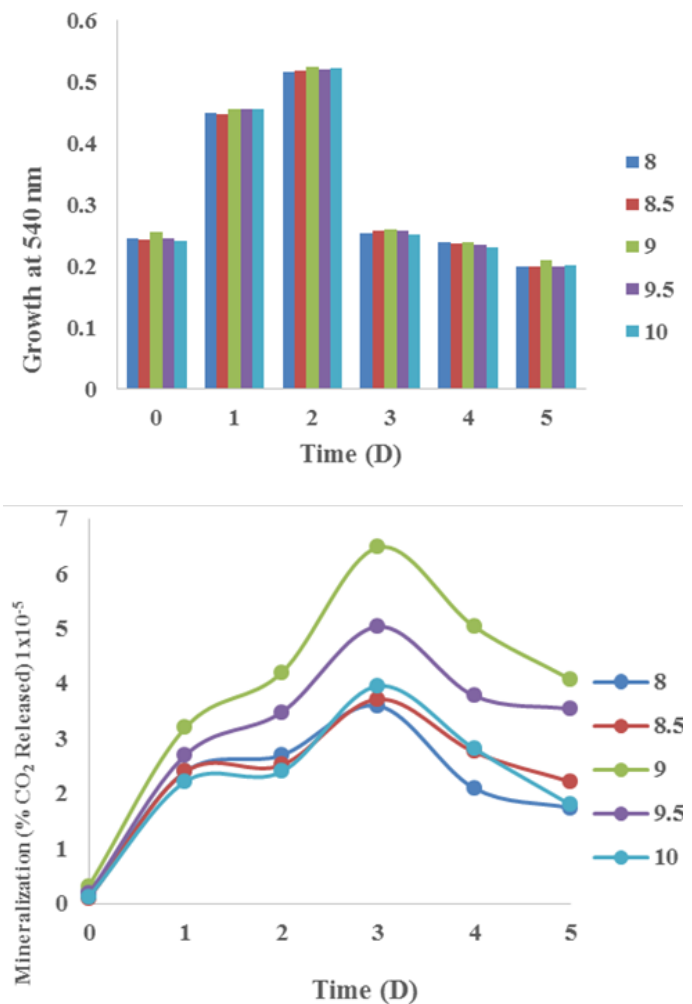

Fig. 5: Growth and Mineralization of Natural Rubber Latex in Different $\mathrm{Ph}$.

\subsubsection{Optimization studies by varying the temperature}

To study the growth of the co-cultured bacterial strains on different temperature $\left(28^{\circ} \mathrm{C}, 37^{\circ} \mathrm{C}, 45^{\circ} \mathrm{C}\right)$ the isolated co-cultured strains were inoculated in Mineral Salts Medium with $10 \%$ latex solution and different temperature. Figure 6 shows the growth and mineralization in different temperatures by the co-cultured bacterial strains. At the end of the experiment it was noted that the cocultured Bacterial strains showed efficient growth and mineralization at $37^{\circ} \mathrm{C}$. Maximum growth on $2^{\text {nd }}$ Day and mineralization of $\left(6.48 \times 10^{-5}\right)$ on the $3^{\text {rd }}$ Day.

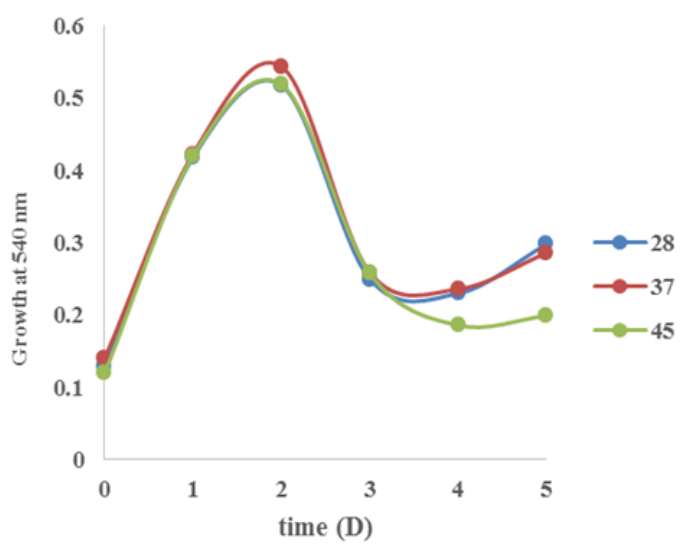




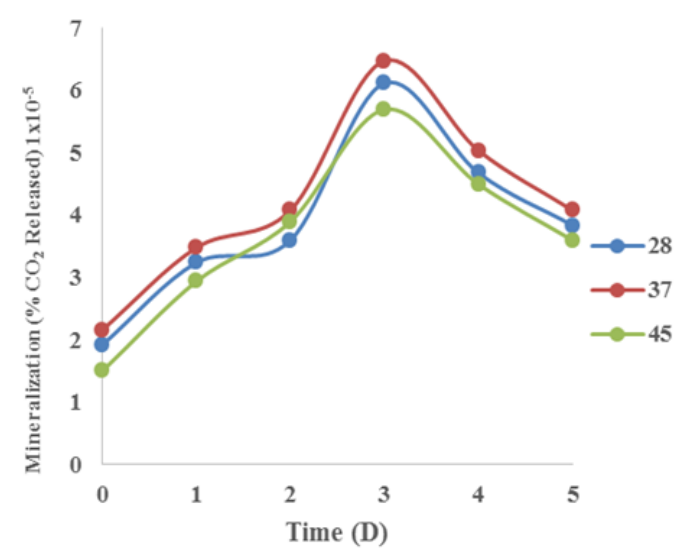

Fig. 6: Growth and Mineralization of Natural Rubber Latex at Different Temperatures.

\subsubsection{Optimization studies by varying carbon and nitrogen}

To enhance the growth and mineralization of the co-cultured bacterial strains different carbon (sucrose, galactose, xylose, and maltose) and nitrogen (peptone, ammonium nitrate, yeast extract, tween) sources. The isolated co-cultured strains were inoculated in Mineral Salts Medium with optimum 10\% latex solution and different carbon and nitrogen sources. Figure 7 and 8 shows the growth and mineralization in different carbon sources by the cocultured bacterial strains. At the end of the experiment it was noted that the co-cultured Bacterial strains showed efficient growth and mineralization in the presence of Sucrose. Maximum growth on $2^{\text {nd }}$ Day and mineralization of $\left(5.4 \times 10^{-5}\right)$ on the $3^{\text {rd }}$ Day
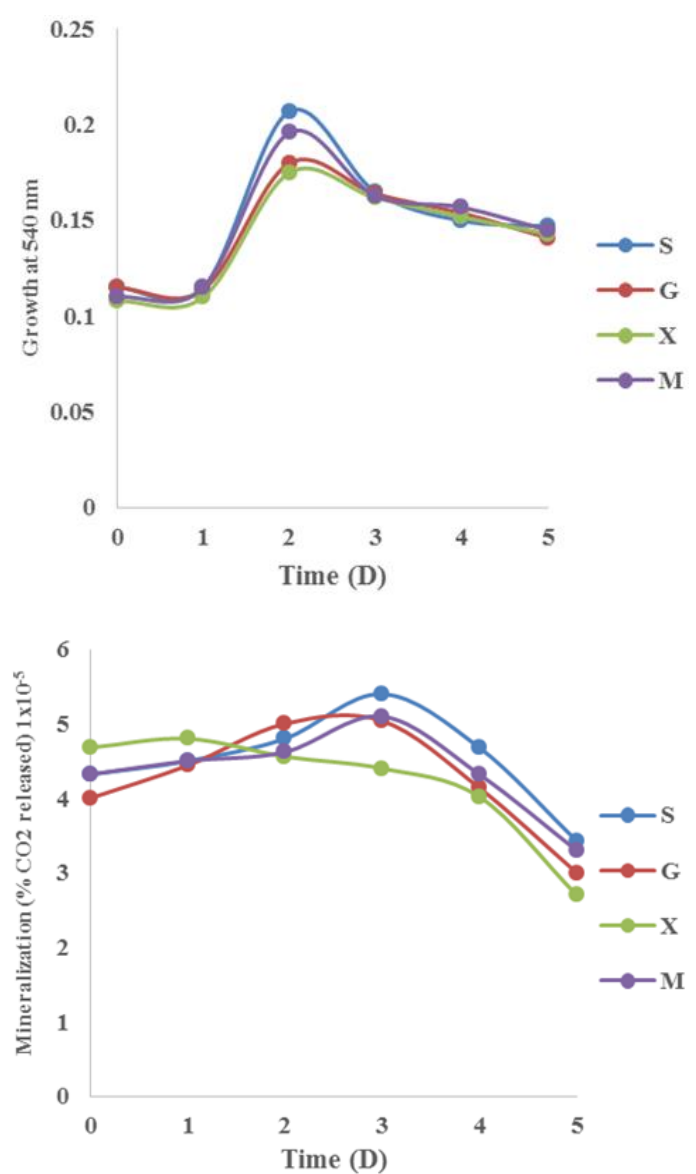

Fig. 7: Growth and Mineralization of Natural Rubber Latex in Different Carbon Sources (S-Sucrose, G-Glucose, X-Xylose, M-Maltose).
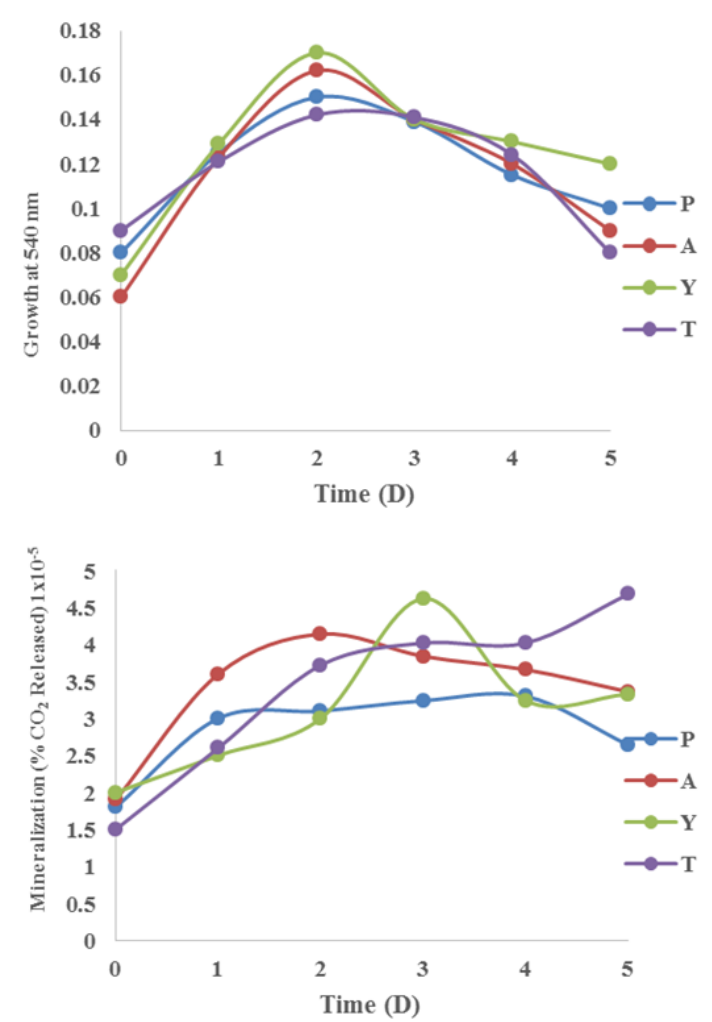

Fig. 8: Growth and Mineralization of Natural Rubber Latex in Differen Nitrogen Sources (P-Peptone, A-Ammonium Nitrate, Y-Yeast Extract, TTween 20.

\subsubsection{To study the products obtained from mineralization of polyisoprene}

Natural rubber was utilized by the bacterial co-cultures were studied for degradation products with FTIR analysis. Figure 9 shows the FTIR spectrum of Natural Rubber on Day 5 (A) and Day 30 (B). Peaks were observed for $1^{\text {st }}$ and $5^{\text {th }}$ Day at the wave length between $1646 \mathrm{~cm}^{-1}$ and $1651 \mathrm{~cm}^{-1}$ respectively having $\mathrm{H}-\mathrm{C}=\mathrm{O}$. C$\mathrm{H}$ stretch and $\mathrm{C}=\mathrm{O}$ stretch which indicates the presence of aldehydes and ketones, as a result of natural rubber mineralization in the mineralized sample. Presence of these aldehyde and ketone group confirms natural rubber degradation. (Nayanashreeet al., 2014).

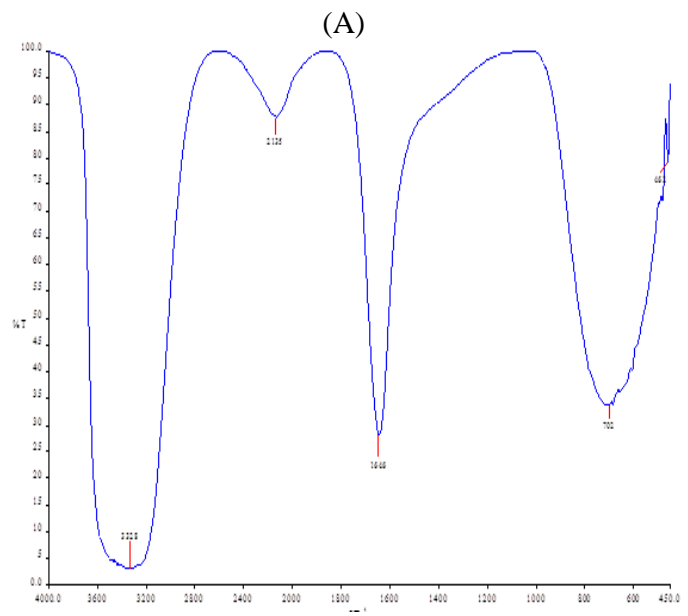


(B)

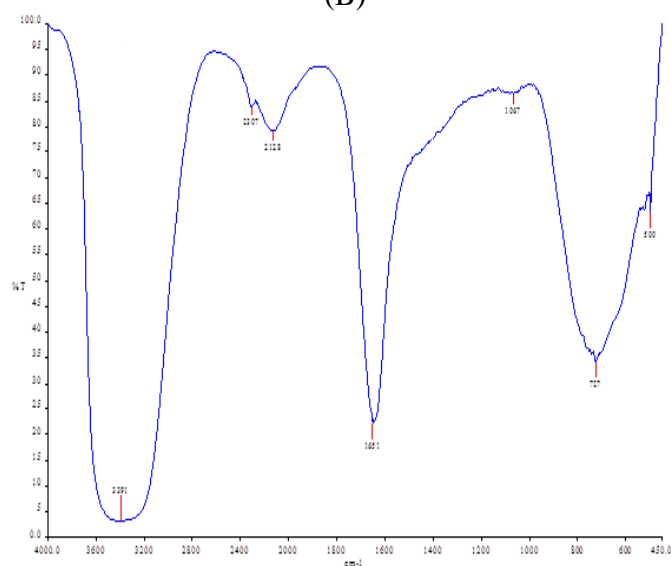

Fig. 9: Confirmation of Natural Rubber Degradation by FTIR

\subsection{Biochemical tests for the two bacterial strains}

Biochemical characterization of the strains was performed using several tests for the identification of the strains. It was observed that strain (MY) showed positive results for Indole tests as it showed the presence of a red ring at the junction of the test tube when Kovac's Reagent was added to the bacterial culture in the Indole Medium. A negative result was recorded for Methyl Red test as there was no red color change on addition of Baritt's Reagent to the inoculated bacterial culture. Absence of pink color on addition of Baritt's Reagent to the same inoculated bacterial culture confirmed the negativity of Voges- Proskauer test. The results forthe Urease test was also recorded as positive since there was color change recorded in the inoculated culture slants. A negative result was recorded for Citrate test with the no color change of the bacterial slant inoculated in the citrate agar from green to Prussian blue. An alkaline butt and alkaline slant was observed as a result of Triple Sugar Agar test.

On performing the biochemical tests for both the strains, it was observed that strain (MW) showed positive results for Indole tests as it showed the presence of a red ring at the junction of the test tube when Kovac's Reagent was added to the bacterial culture in the Indole Medium. A negative result was recorded for Methyl Red test as there was no red color change on addition of Baritt's Reagent to the inoculated bacterial culture. Absence of pink color on addition of Baritt's Reagent to the same inoculated bacterial culture confirmed the negativity of Voges- Proskauer test. The results for the Urease test were also recorded as positive since there was color change recorded in the inoculated culture slants. A positive results was recorded for Citrate test with the change in color of the bacterial slant inoculated in the citrate agar from green to Prussian blue. An Acidic butt and Acidic Slant were observed as a result of Triple Sugar Agar test.

\subsection{Genomic DNA extraction and PCR amplification}

The genomic DNA was isolated from each bacterial isolates, PCR amplification was performed and the unknown bacterial strains were identified through $16 \mathrm{~S} \mathrm{r}$ RNA sequencing. The bacterial isolates were identified from the sequences using BLAST tool. Genomic DNA and PCR amplified products of the bacterial isolates are shown in Figure 10.

\subsection{Identification of the bacterial strains present in the co-culture bacterial strains by phylogenetic analysis}

\subsubsection{Description of Bacillus cohnii}

Phylogenetic analysis based on nucleotide sequences from MY strain showed a maximum of $96 \%$ identity towards Bacillus cohnii strain NBRC 15565. Hence, MY was identified as Bacillus cohnii. The strain belongs to the phyla Firmicutes, is a motile gram positive rod shaped bacteria that are naturally found in soil. According to biochemical tests, this strain showed positive result for Methyl red, Voges-proskauer, Citrate and Triple sugar agar test and negative indole. Figure 11 shows the neighbouring species for MY.

\subsubsection{Description of Brevundimonas naejangsanensis}

Phylogenetic analysis based on nucleotide sequences from the MW strain showed a maximum of $96 \%$ identity towards Brevundimonas naejangsanensis strain BIO-TAS2-2. Hence, MW was identified as Brevundimonas naejangsanensis. The strain belongs to the phyla Firmicutes, is a motile gram positive rod shaped bacteria that are naturally found in soil. According to biochemical tests, this strain showed positive result for Methyl red, Voges-proskauer, Citrate and Triple sugar agar test and negative indole. Figure 12 shows the neighbouring species for MW.

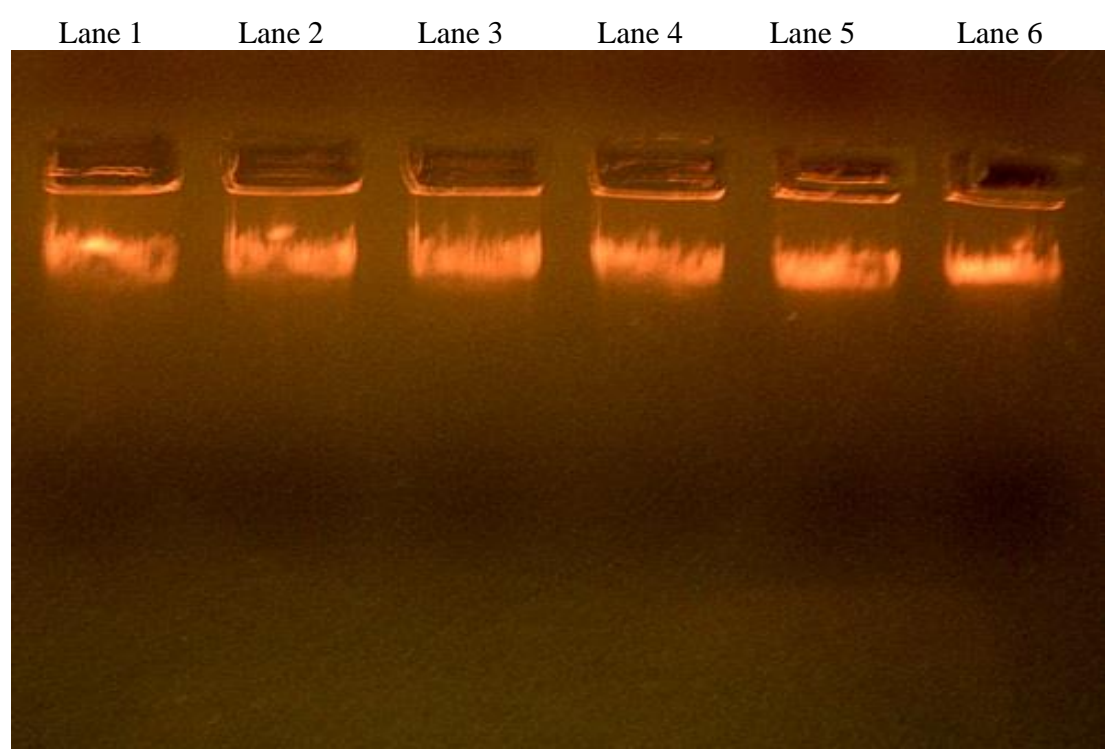

Fig. 10: Lane 5 = Genomic DNA of MY; Lane $6=$ Genomic DNA of MW 


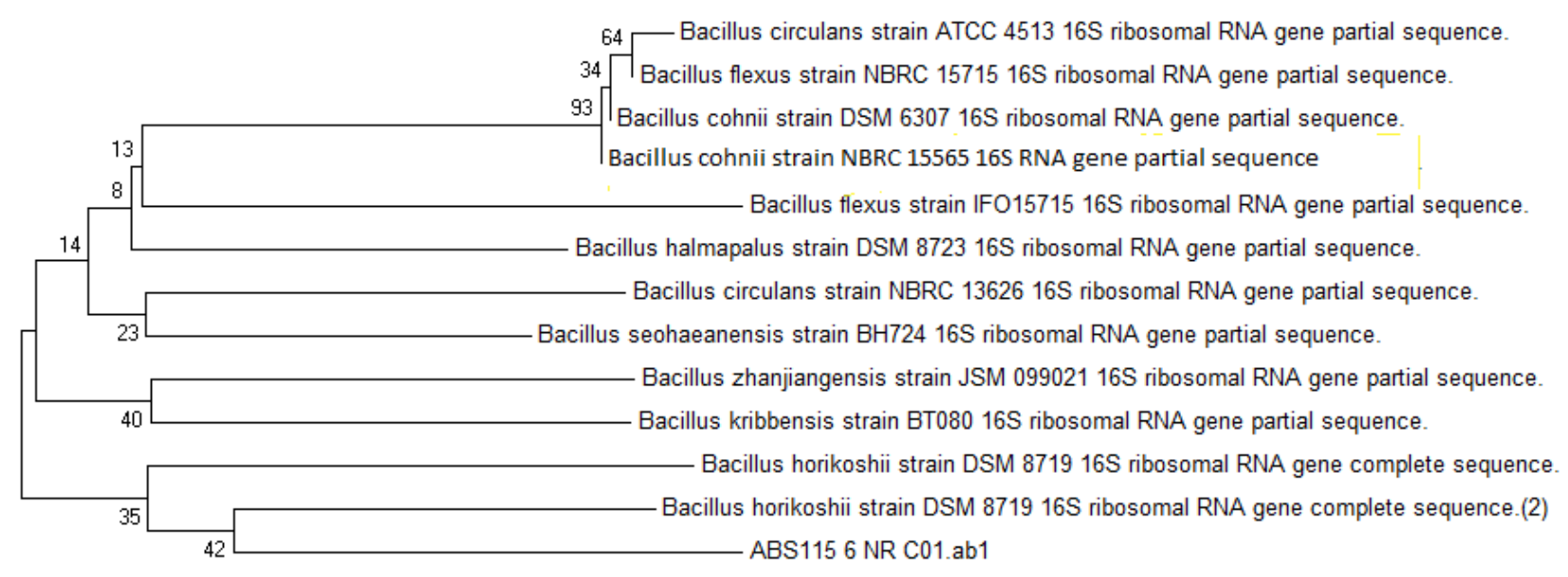

Fig. 11: Bootstrapped Phylogenetic Analysis of Bacillus cohinii Strain with Its Nearby Sequences

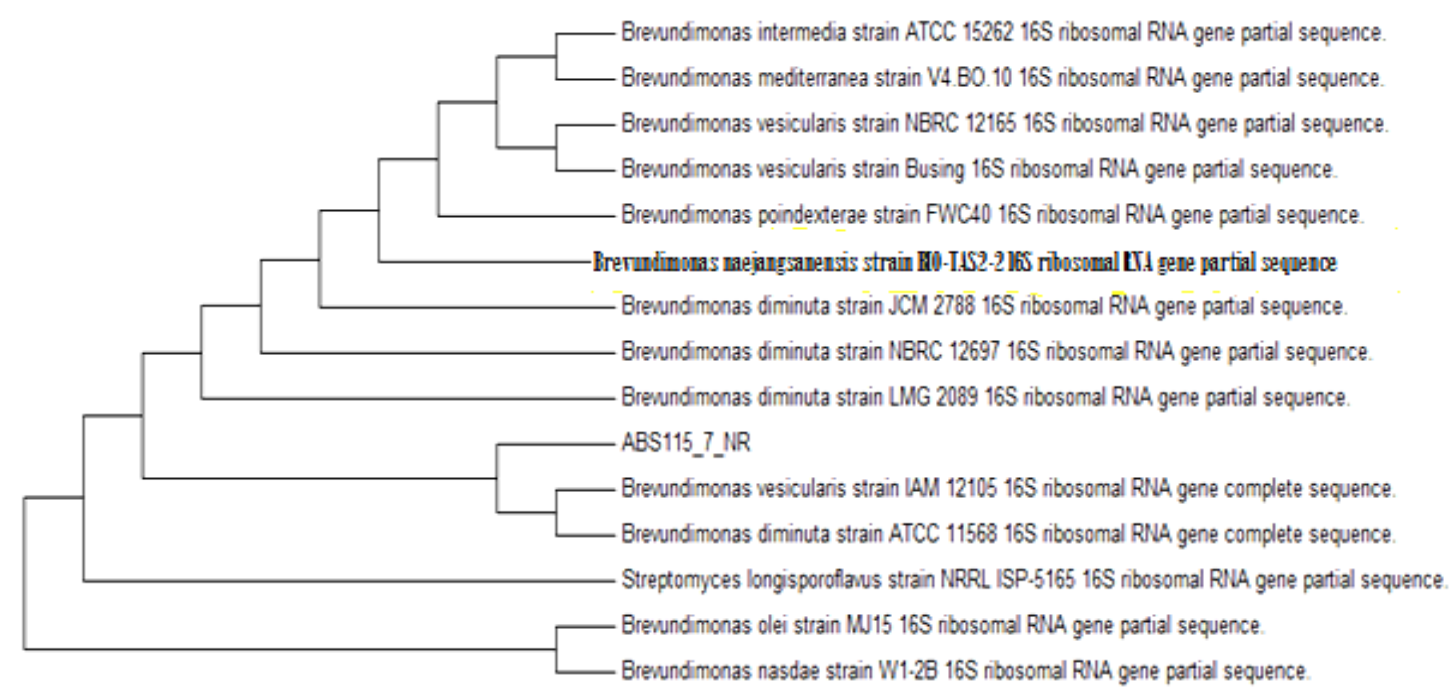

Fig. 12: Phylogenetic Analysis of Brevundimonas naejangsanensis Strain with Its Nearby Sequence

\section{Discussion}

Rubber products are widely used in our daily life these products are mainly made up of Natural rubber (NR) which is obtained from the latex of tree Hevea brasiliensis commonly called Rubber tree. After usage of these natural rubber products the disposal of these products are the world wide solid waste problem. One of the solutions to reduce this problem is to recycle the used waste rubber. But due to the chemical cross linking formed during vulcanization it is not possible to simply melt and reshape the products as in case of polythene. So other alternatives such as microbial degradation of the product should be developed. Microbial degradation is mainly carried out by various microorganisms such as bacteria and fungi.

Berekaa et al., (2000) conducted similar work and tested the biodegrading ability of different bacteria belonging to the genera Gordonia (strains $\mathrm{Kb} 2, \mathrm{Kd} 2$ and $\mathrm{VH} 2$ ), Mycobacterium, Micromonospora and Pseudomonas sp. All strains were able to used NR as well as NR latex gloves as sole carbon source. Roy et al. (2005) made an attempt to study on natural rubber biodegradation through solid-state fermentation (SSF) and sub-merged fermentation (SMF) has been carried out for both bacterial as well as fungal species. There was a change in the organic car bon content along with the average molecular weight of the treated rubber samples indicated rubber hydrocarbon utilization and its degradation. In the present study an attempt was made to isolate rubber degrading microorganisms from the soil isolated from rubber plantation area.
Nayanshree et al., (2014) isolated bacterial strain Bacillus pumilus have the capacity to degrade Natural rubber by $29.3 \%$ and it can be useful in solving the problem caused by waste Natural rubber products in the environment. In the present study two bacterial strains were isolated and were identified as Bacillus cohnii and Brevundimonas naejangsanensis which were able to mineralize natural rubber upto $3.6 \times 10^{-5}$ on the $4^{\text {th }}$ Day.

Nayanshree et al., (2013) worked with some more microorganisms that can mineralize natural rubber such as Aspergillus sp and Penicillium sp. In the time interval of 2 months Aspergillus niger showed $28.3 \%$ degradation and Penicillium showed $25.9 \%$ degradation. They have also worked with enzymes such as Laccase and Manganese that were responsible for the degradation of the polymer. In the present study it was observed that the co-cultured bacterial strains were able to mineralize natural rubber latex up to a concentration of $50 \%$, in which optimum mineralization was observed at $10 \%$ concentration within 5 days of incubation.

In another study, rubber- degrading bacterial isolate was enriched from soil sample and according to biochemical and molecular characterisation analysis; it was identified as Achromobacter sp. NRB. The obtained strain was able to degrade and mineralize raw natural rubber granules as well as some forms of tire rubber and to use it as a sole source for carbon. But in contrast to the growth in common media where carbon source is dissolved, the growth of microorganisms on natural rubber products is very slow and the effect of culture conditions upon microbial growth on the insoluble solid substrate like rubber has not been well characterized (Berekkaa et al., 2005). 
In the present study, rubber- degrading bacterial co-culture was enriched by different carbon sources (Sucrose, Galactose, Xylose, and Maltose) and nitrogen (Peptone, Ammonium Nitrate, Yeast Extract, Tween) sources. From the experiments it was observed that yeast extract served as a better nitrogen source that enhanced the mineralisation of latex at its maximum by the bacterial coculture. Likewise, sucrose was found to be the best carbon source that could enhance the mineralisation percentage of natural rubber. Addition of yeast extract as the nitrogen source and sucrose as the carbon source in the mineral salts medium enhanced the mineralization of natural rubber where the mineralization reduced by one day.

Nayanshree et al., (2014) analysed the degradation of natural rubber was studied by carrying out growth experiment in MSM, and degradation was confirmed by staining with Schiff's reagent, SEM, and FTIR studies. Peaks which were observed at 1662.34 $\mathrm{cm}^{-1}$ having $\mathrm{H}-\mathrm{C}=\mathrm{O}, \mathrm{C}-\mathrm{H}$ stretch and $\mathrm{C}-\mathrm{O}$ stretch which indicates the presence of aldehydes and ketones which confirms the degradation of rubber. In the present study peaks were observed at 1646 $\mathrm{cm}^{-1}$ and $1651 \mathrm{~cm}^{-1}$ having $\mathrm{H}-\mathrm{C}=\mathrm{O}, \mathrm{C}-\mathrm{H}$ stretch and $\mathrm{C}-\mathrm{O}$ stretch which indicates the presence of aldehydes and ketones which confirms the degradation of rubber.

AbdeiL Atif Heshama et al., (2015) has also conducted a similar study. In their study the degrading ability of Ficuselastica rubber latex by a bacterium strain ASU03, isolated from Egyptian soil was assessed. The strain was able to produce clear zone around its colony on latex rubber containing medium and was identified by conventional methods as Streptomyces sp. Phylogenetic analysis of 16S $r$ RNA (16S $r$ RNA) was also performed. The degradation of Ficuselastica rubber latex was determined by measuring the increase in protein content of bacterium $(\mathrm{mg} / \mathrm{g}$ dry $\mathrm{wt})$, reduction in molecular weight $(\mathrm{g} / \mathrm{mol})$ and inherent viscosity $(\mathrm{dL} / \mathrm{g})$ of the latex. Moreover the degradation was also confirmed by formation of aldehyde or keto group by Schiff's reagent and by observing the growth of the Streptomyces strain using scanning electron microscopy.

\section{Conclusion}

Rubber products are widely used in our daily life. These products are made up of natural vulcanized rubber and other chemical additives. Due to vulcanization of the natural rubber these rubber are very resistant to high temperature and persist in environment for very long time. Rubber materials have been increasingly used now days in different area after usage its disposal is a very big solid waste problem. It cannot be easily recycled due to the sulphur cross linking formed during vulcanization. If they are burnt they release enormous amount of carbon-di-oxide and some other gases which cause environmental pollution and contribute to the global warming. Rubber products such as balloon which are disposed in the natural environment are considered to be dangerous to wild animals if they are consumed by animals. One of the alternative ways to solve these problems is to subject these products to biodegradation. During the present study the isolated strains Bacillus cohnii and Brevundimonas naejangsanensis were found to mineralize both natural and artificial rubber. The isolated co-cultures were also applied for the degradation of plastics and bioplastics. Thus these strains can be used as an eco-friendly method for the degradation of these polymers. Future prospects of this study could be application of these strains in the contaminated soil containing rubber and plastic wastes.

\section{Acknowledgement}

I express my sincere thanks to Department of Biotechnology, Stella Maris College and for providing all facilities for successful completion of the project. It has been a great learning experience working under my guide Dr. K Veena Gayathri, Assistant Professor, Department of Biotechnology, Stella Maris College. My heartfelt gratitude to my Parents for their blessings, moral support and constant encouragement. I sincerely thank each and every one who had been associated with the completion of this work directly or indirectly.

\section{References}

[1] Berekaa M.M.,Barakaat A., El-Sayeed S.M. \& El-Aassar S. A. (2005) Degradation of Natural Rubber by Achromobacter sp. NRB and Evaluation of culture conditions, Polish Journal of Microbiology . 54, (1), 55-62.

[2] Cui Q., Wang L., Huag Y., Liu Z. \& Goodfellow M. (2005), Nocardiajiangxiensis sp. nov.and Nocardiamiyunensis sp. nov., isolated from acidic soils. International Journal of Systematic and Evolutionary Microbiology. 55: 1921-1925. http://dx.doi.org/10.1099/ijs.0.63644-0.

[3] Lee, K.M., Gimore, D.F. \& Huss M.J. (2005), Fungal Degradation of the Bioplastics PHB, Journal of Polymer and the environment. 13, DOI 10.1007/s10924-005-4756-4.

[4] Rose K. \& Steinbuchel A. (2005) Biodegradation of natural rubber and related compounds: Recent insights into a hardly understood catabolic capability of microorganisms, Applied and Environmental Microbiology. 71: 2803-2812 http://dx.doi.org/10.1128/AEM.71.6.2803-2812.2005.

[5] Rose K., Tenberge K. B. \& Steinbuchel A. (2005). Identification and characterization of genes from Streptomyces sp. strain K30 responsible for clear zone formation on natural rubber latex and poly (cis-1, 4-isoprene) rubber degradation, Biomacromolecules 6, (1), 180- 188. http://dx.doi.org/10.1021/bm0496110.

[6] Yamamura H., Hayakawa M., Nakagawa Y., Tamura T., Kohno T., Komatsu F. \& Limura Y. (2005), Nocardia takedensis sp. nov., isolated from moat sediment and scumming activated sludge". International Journal of Systematic and Evolutionary Microbiology. 55 433-436. http://dx.doi.org/10.1099/ijs.0.63189-0.

[7] Ibrahim E. M. A., Arenskotter M., Luftmann H. \& Steinbuchel A. (2006). "Identification of poly (cis-1, 4- isoprene) degradation intermediates during growth of moderately thermophilic Actimycetes on rubber and cloning of a functional ICP homologue from Nocardia farcinica strain EI". Applied Environmental Microbiology 72: 3375-3382. http://dx.doi.org/10.1128/AEM.72.5.3375-3382.2006.

[8] Roy R.V., Das M., Banerjee R. \& Bhowmick A. K. (2006). Comparative studies on cross linked and uncross linked natural rubber biodegradation by Pseudomonas sp. Bio resource Technology. 97, 18, 2485-2488. http://dx.doi.org/10.1016/j.biortech.2005.09.024.

[9] Roy R.V., Das M., Banerjee R. \& Bhowmick A. K. (2006). Comparative studies on cross linked and uncross linked natural rubber biodegradation by Pseudomonas sp. Bio Resource Technology, 97, 18, 2485-2488. http://dx.doi.org/10.1016/j.biortech.2005.09.024.

[10] Yu L., Dean K. \& Li L. (2006). Polymer blends and composites from renewable resources. Progress in Polymer Science. 31, 6, 576602. http://dx.doi.org/10.1016/j.progpolymsci.2006.03.002.

[11] Seo S. J., Keum Y. S., Harada R. M. \& Li Q. X. (2007). Isolation and characterization of bacteria capable of degrading polycyclic aromatic hydrocarbons (PAHs) and organophosphorus pesticides from PAH-contaminated soil in Hilo, Hawaii. Journal of Agricultural and Food Chemistry, 55, (14), 5383-5389. http://dx.doi.org/10.1021/jf0637630.

[12] Seo S.J., Keum Y.S., Harada R.M. \& Li Q. X. (2007). Isolation and characterization of bacteria capable of degrading polycyclic aromatic hydrocarbons (PAHs) and organophosphorus pesticides from PAH-contaminated soil in Hilo, Hawaii. Journal of Agricultural and Food Chemistry.55, (14), 5383-5389. http://dx.doi.org/10.1021/jf0637630.

[13] Warneke S., Arenskotter M., Tenberge K. B. \& Steinbuchel A. (2007). Bacterial degradation of poly (trans-1, 4-isoprene) (Guttapercha). Microbiology 153, (2), 347- 356 http://dx.doi.org/10.1099/mic.0.2006/000109-0.

[14] Aamer Ali Shah., FariahHaasan, Abdul Hameed., \& Safia Ahmed (2008) Biodegradation of plastics: A Comprehensive Review, Biotechnology Advances 246-265.

[15] Cherian E. \& Jayachandran K. (2009). Microbial degradation of natural rubber latex by a novel species of Bacillus sp. SBS 25 isolated from soil, International Journal of Environmental Research, 3, (4), 599-604.

[16] Tanrattanakul V. \& Chumeka W.(2009). Effect of potassium persulfate on graft copolymerization and mechanical properties of cassava starch/natural rubber foams. Journal of Applied Polymer Science.116, (1), 93-105. http://dx.doi.org/10.1002/app.31514.

[17] Wang Z. F., Peng Z., Li S. D., Lin H., Zhang K. X., She X. D. \& Fu X. (2009). The impact of esterification on the properties of 
starch/natural rubber composite. Composites Science and Technology. 69, (11-12), 1797-1803. http://dx.doi.org/10.1016/j.compscitech.2009.04.018.

[18] Ziaullah Shah, Aamer Ali Shah, Abdul Hameed \& Fariha Hasan. (2009). Effect of pretreatments on enhanced degradation of polyisoprene rubber by newly isolated Bacillus sp. Strain S10. Journal of the Chemical Society of Pakistan. 31, (4), 638-646.

[19] Desmond Threadingham, Werner Obrecht, Wolfgang Wieder, Gerhard Wachholz and Rüdiger Engehausen. (2011) "Rubber, 3. Synthetic Rubbers, Introduction and Overview" in Ullmann'sEncyclopedia of Industrial Chemistry. Weinheim. http://dx.doi.org/10.1002/14356007.a23_239.pub5.

[20] SirimapornWatcharakul, KamontamUmsakul, Brian Hodgson, WannapaChumeka, \& Varaporn Tanrattanakul. (2012). Electronic Journal of Biotechnology, 15, 1. ISSN: 0717-3458

[21] Nayanashree.G \& Thippeswamy.B, (2013) Natural Rubber Degradation By Aspergillus niger and Penicillium sp. International Journal of Recent Scientific Research 4,(9),1337- 1341.

[22] Nayanashree.G, Thippeswamy.B \& Krishnappa.M (2014) Natural Rubber Biodegradation by Cladosporium fulvum and Enzymes responsible for Biodegradation International Journal of Advanced Research, 2, (4), 1206-1212.

[23] Nayanashree.G, Thippeswamy.B, \& Krishnappa.M (2014) Enzymatic studies on Natural rubber Biodegradation by Bacillus pumilus, International Journal of Biological Research, 2 (2) 44-4.

[24] Abd ElLatif Heshama , Nadia H. Mohamedb, Mady A. Ismail \& Ahmed A.M. Shoreit Microbiology, 84, (3),351-358. 